\title{
Социальные инновации: содержание, субъектные формы и классификация
}

\author{
Т. Д. Ромащенко ${ }^{1}$, А. Е. Кисова ${ }^{2 凶}$ \\ ${ }^{1}$ Воронежский государственный университет, Университетская пл., 1, \\ 394018, Воронеж, Российская Федерация \\ 2 Липецкий государственный технический университет, ул. Московская, 30, \\ 398055, Липецк, Российская Федерация
}

Для цитирования: Ромащенко Т. Д., Кисова А. Е. Социальные инновации: содержание, субъектные формы и классификация // Вестник Воронежского государственного университета. Серия: Экономика и управление. 2020. T. 3. С. 25-33. DOI: 10.17308/econ.2020.3/3102

\begin{abstract}
Предмет. Социальные инновации являются объектом пристального внимания многих отечественных и зарубежных экономистов на протяжении последних двадцати лет. Для их изучения характерен междисциплинарный подход. Тем не менее многие важные аспекты данного явления недостаточно изучены или носят дискуссионный характер. К числу последних относятся сущность социальных инноваций, их особенности и содержательные характеристики, субъектные формы. Перечисленные причины приводят к необходимости классификации социальных инноваций по ряду признаков, с помощью которых можно идентифицировать их категориальный статус, выявить отличительные особенности от таких категорий, как инновации в социальной сфере и инновации в общественном секторе.

Цели. Авторское исследование содержания социальных инноваций. Изучение субъектных форм социальных инноваций с позиций проектного и институционального подходов. Классификация социальных инноваций по критериальным признакам: сферам общественной жизни, уровню и степени масштабности, институциональной форме выражения, субъектам взаимодействия.

Методология. В процессе достижения поставленных целей применялась совокупность научных подходов: историко-генетического, системного, проектного, институционального, структурного. В работе использованы приемы и методы формальной и диалектической логики (анализа и синтеза, сравнений, аналогий, единства исторического и логического). Исследование построено на изучении актуальной монографической и периодической экономической литературы.

Выводы. Сделан вывод о понимании социальных инноваций как совокупности качественных изменений в сферах формирования, развития и реализации человеческого и социального капитала с целью повышения уровня личного и общественного благосостояния. Специфика социальных инноваций определяется их характеристиками: стратегической направленностью, инертностью, синергизмом, рискогенностью. Участники социально-инновационного процесса рассматриваются с позиций проектного и институционального подходов. В рамках проектного подхода основными субъектами являются заказчик, инвестор, производитель, потребитель; в рамках институционального - домохозяйства, фирмы, государство. Типология социальных инноваций характеризуется большим разнообразием, многокритериальностью и значима как в теоретическом, так и в прикладном аспектах, поскольку позволяет сформировать целостное и завершенное представление об исследуемом объекте, а также выявлять приоритетные направления их развития.
\end{abstract}

Ключевые слова: качественные изменения, виды социальных инноваций, классификационные признаки, социальное партнерство, социальное предпринимательство.

\section{Введение}

Одним из активно обсуждаемых в научной литературе вопросов является статус социальных инноваций как самостоятельного явления общественной и экономической жизни. Рассматриваются в основном вопро- сы, связанные с идентификацией их сущности и содержания, роли государства в социально-инновационном процессе, а также отличия данного явления от таких, как инновации в общественном секторе и инновации в социальной сфере.

() Ромащенко Т. Д., Кисова А. Е., 2020

Вестник ВГУ. Серия: Экономика и управление. 2020. № 3. С. 25-33. 
Кроме того, как отмечают А. Ю. Веретенникова и Ж. К. Омонов: «Рост интереса к социальным инновациям как объекту научного исследования наблюдается последние двадцать лет, что обусловлено как поиском альтернативных способов решения проблем общественного сектора, так и трансформацией отношений между экономическими агентами, вызванной стремительным технологическим развитием, смещением интересов и стимулов отдельных экономических агентов в социальную, культурную, экологическую и другие сферы» [16].

Отметим, что инновации вообще и социальные инновации в частности являются неотъемлемой частью социально-экономического развития, поскольку предполагают качественные изменения всех его факторов и результатов. В связи с этим одним из основополагающих аспектов изучения данного явления является развитие теоретико-методологических представлений о содержательной основе социальных инноваций.

Таким образом, актуальность исследования содержательной основы социальных инноваций обусловлена следующими как объективными, так и субъективными причинами на различных уровнях экономики:

- поиском альтернативных способов решения общественных проблем;

- изменением отношений между экономическими агентами;

- эволюционированием социально-экономических систем, переходом от одного технологического уклада к другому.

Анализ современных научных исследований в области формирования и развития социальных инноваций представлен в трудах различных зарубежных и российских исследователей: А. В. Башариной, А. Ю. Веретенниковой, С. Вил, Ю. А. Гаджиева, Г. А. Гончарова, Н.В.Лазаревой, А. В. Негожиной, Ж. К. Омонова, Т. С. Пантелевой, Е. В. Попова, Г. Дж. Филса и др.

Целью данной работы является развитие теоретико-методологических представлений о содержательной основе социальных инноваций, выявление их субъектных форм и классификационных признаков. В соответствии с установленной целью были поставлены следующие задачи:

- во-первых, на основе теоретического анализа выявить основные характеристики социальных инноваций и предложить авторскую трактовку данного явления;

- во-вторых, обосновать участников социально-инновационного процесса с позиций проектного и институционального подходов;
- в-третьих, определить классификационные признаки типологии социальных инноваций.

\section{Материалы и методы исследования}

Теоретической и методологической основой статьи выступают научные достижения ученых в области исследования сущностных и содержательных основ социальных инноваций, их субъектных форм, а также различных классификационных признаков. Для обоснования результатов исследования применялась совокупность научных подходов: историко-генетического, системного, проектного, институционального, структурного. В работе использованы приемы и методы формальной и диалектической логики (анализа и синтеза, сравнений, аналогий, единства исторического и логического).

Исследование опирается на монографии, материалы периодических изданий, научные статьи, выполненные по изучаемой проблематике.

\section{Обсуждение результатов}

Анализ научной литературы показал, что в настоящее время отсутствует единая методологическая проработка понимания социальных инноваций. Если обратиться к определению Т. С. Пантелеевой, то социальные инновации это результат научной разработки, организации и применения нового, удовлетворяющего потребности человека и общества и вызывающего вместе с тем социальные изменения [17].

А. В. Негорожина, Н. В. Лазарева определяют социальные инновации как «новые идеи, стратегии, технологии, способствующие решению социально-значимых задач, которые вызывают социальные изменения общества» [15].Г.Дж.Филс в определении социальных инноваций делает акцент на том, что это в первую очередь «любое новое и полезное решение, направленное на социальные потребности или проблемы, которые лучше существующих подходов (например, более эффективны, результативны, устойчивы) и для которых значение созданной ценности (выгод) направлено в первую очередь для общества в целом, чем для отдельного человека [4]. Иными словами, ученый подчеркивает, что результатом социальных инноваций является в первую очередь рост общественного благосостояния, а не личного. Оппонентом данного утверждения выступает С. Вил, считая, что «предполагаемая новая идея имеет потенциал для улучшения либо качества, либо длительности жизни» [5].

По мнению А. В. Башариной, социальные инновации целесообразно рассматривать как 
Социальные инновации: содержание, субъектные формы и классификация

процесс обновления сфер жизни человека в реорганизации социума (педагогика, система управления, благотворительность, обслуживание, организация процесса) [7]. Она считает, что «социальные инновации представляют собой явления в социальной системе общества, которых не было на предыдущей стадии его развития и которые возникли естественным образом либо введены по инициативе субъектов управления - государства, церкви и других социальных институтов. Формализация социальных инноваций в виде регламентирующих документов обычно завершает процесс их интеграции в социальную структуру» [7].

Ю.А. Гаджиев подчеркивает, что инновации это сложный социальный процесс, который включает координацию некоторого количества социальных участников с различной квалификацией и компетенцией. Она выделяет такие черты данного процесса, как неоднозначность и неопределенность, уточняя при этом, что «копирование неопределенности путем собирания дополнительной информации и знаний можно рассматривать как неотъемлемую характеристику инновационных процессов» [10].

Г. А. Гончаров рассматривает социальные инновации в рамках исследования социального капитала и определяет их как «управляемые качественные позитивные изменения, связанные с трансформацией принятых норм поведения, повышением эффективности институтов, ростом уровня организационного взаимодействия между акторами, обеспечивающими социально-экономическую устойчивость хозяйствующих субъектов» [11].

В целом по результатам проведенного теоретического анализа трактовок социальных инноваций и практик их внедрения можно сделать следующие выводы:

- во-первых, вышеперечисленные авторы при исследовании социальных инноваций в большинстве своем связывают их лишь с общественной деятельностью человека, обособленной от иных видов деятельности (экономической, политической, духовной). Это представляется неоправданным, поскольку, по нашему мнению, согласно системному подходу все находится во взаимосвязи, взаимообусловленности и взаимоопределенности;

- во-вторых, основными составляющими социальных инноваций являются такие элементы, как новшество; необратимые изменения в сферах жизнедеятельности человека; решение общественных проблем; рост благосостояния - общественного и личного.
Необходимо уточнить, что новшество может как определяться с позиции предметного подхода (воплощаться в форме социальной услуги, продукта, проекта), так и носить процессный характер, принимая форму социально-инновационного процесса [3]. В любом случае социальная инновация реализуется в сферах деятельности человека с целью улучшения качества его жизни, повышения благосостояния.

Таким образом, по нашему мнению, социальные инновации - это совокупность качественных изменений в сферах формирования, развития и реализации человеческого и социального капитала с целью повышения уровня личного и общественного благосостояния.

Качественная определенность социальных инноваций обусловлена рядом их характерных особенностей.

1. Стратегическая направленность. Создание и внедрение социальных инноваций представляется собой ключевой фактор трансформации социально-экономической системы в долгосрочной перспективе.

2. Инертность. Инновационной инертностью социально-экономической системы являются любые действия ее субъектов, направленные на задержку или противодействие осуществлению инноваций в организации [8]. Проявляется в противодействии отдельного субъекта и/или всех субъектов инновациям, неприятии новых практик, процессов и структур, представляющих собой значительный отрыв от традиционных норм и связанных с экономическими и социальными условиями функционирования данной социально-экономической системы [13]. Инновационная инертность социально-экономической системы может проявляться в таких формах, как отсутствие убежденности в своевременности и необходимости инноваций, отсрочка начала процесса изменений, попытки саботировать изменения внутри организации, отсутствие готовности принять личное участие в мероприятиях по осуществлению нововведений.

3. Синергия. Внедрение социальных инноваций может сопровождаться возникновением эффекта синергии благодаря взаимодействию различных хозяйствующих субъектов между собой [14]. Примером может выступить так называемое государственное социальное частное партнерство, когда происходит тесное сотрудничество коммерческих и некоммерческих организаций с государственными органами власти с целью решения конкретных социальных проблем территории. 
4. Рискогенность. Социальные инновации по своей природе характеризуются большим уровнем риска, нежели, например, технологические, поскольку их формирование, распространение и внедрение в практику зависит от качества социального капитала в социальноэкономической системе.

Заметим, что социальные инновации являются достаточно сложным социально-экономическим явлением, поскольку возникают на стыке экономической и социальной сферы. В соответствии с данным утверждением, по нашему мнению, участников социально-инновационного процесса необходимо рассматривать в позиции проектного и институционального подходов.

С одной стороны, согласно проектному подходу участниками социальных инноваций являются [9]:

- заказчик, в роли которого могут выступать федеральные, региональные, муниципальные органы власти и управления, выполняющие задачу социального обеспечения общества и решения социальных проблем;

- инвестор, в качестве которого могут выступать как государственные и муниципальные органы власти, так и различные фонды, благотворительные организации, частные компании, а также отдельные индивиды;

- производитель, представленный инициатором социальных инноваций. Это могут быть представители бизнеса, объединения государственных органов власти и бизнеса, отдельные индивиды;

- потребителем, в роли которого выступают общество в целом и человек в частности.

С позиции институционального подхода участниками социальных инноваций являются домохозяйства, фирмы и государство. Роль и функции домохозяйств необходимо рассматривать двояко: с одной стороны, они выступают в качестве носителя человеческого капитала, являющегося потенциальной основой для создания социальной инновации, с другой - как непосредственный потребитель социальной инновации [12].

Формирование, распространение и внедрение социальных инноваций в различные сферы жизнедеятельности человека порождает возникновение различных их видов и типов [20]. Например, к социальным инновациям в настоящее время многие экономисты относят чартерные школы [6], социальные контракты [1], микрофинансирование [18], социальное предпринимательство [2; 19] и др.
Поскольку само по себе данное явление считается, во-первых, новым в экономической науке, недостаточно изученным, а, во-вторых, сложной междисциплинарной категорией, то в данное время не существует единой классификации социальных инноваций. Типология социальных инноваций характеризуется большим разнообразием и имеет многокритериальный характер [18]. При этом выбор типологии зависит от целей проводимого исследования.

На наш взгляд, основными классификационными признаками социальных инноваций являются следующие: по сферам общественной жизни, по уровню и степени масштабности, по институциональной форме выражения, по субъектам взаимодействия.

По сферам общественной жизни можно выделить инновации в социальной, экономической, политической, культурно-духовной сферах.

По уровню и степени масштабности социальные инновации подразделяются на инновации нано-, микро-, макро- и мегауровня.

По институциональной форме выражения социальных инноваций различают социальное предпринимательство, социальные кооперации, некоммерческие организации.

По субъектам взаимодействия, по нашему мнению, социальные инновации целесообразно разделить на два вида:

- взаимодействие бизнеса и государственных органов власти (государственное социальное частное партнерство (ГСЧП), благотворительные проекты);

- взаимодействие предприятий, домашних хозяйств и государства - социальное партнерство.

Остановимся подробно на характеристиках основных, наиболее значимых, на наш взгляд, видов социальных инноваций. Так, под социальным предпринимательством понимается предпринимательская деятельность, нацеленная на смягчение или решение социальных проблем, характеризующаяся следующими признаками: социальное воздействие, инновационность, самоокупаемость, масштабность, тиражируемость. Оно сочетает в себе социальную направленность деятельности и предпринимательский подход, находится на стыке предпринимательства и благотворительности и предполагает создание социального блага не через чистую благотворительность, а через прибыльную или частично прибыльную деятельность [7]. Основная цель социальных предприятий - это решение социальных проблем инновационным методами, т. е. создание со- 
Социальные инновации: содержание, субъектные формы и классификация

циального блага, посредством осуществления предпринимательской деятельности.

Социальное предприятие представляет собой «родовой термин для обозначения некоммерческого предприятия или коммерческой деятельности, которая ведется с целью проведения положительных социальных изменений и одновременно опирается на финансовые результаты» [12]. Данная категория, кроме того, включает такие традиционные организации, как некоммерческие театры, госпитали, школы, производителей социальных услуг и т. д. Отличают данные организации следующие характеристики: покрытие собственных издержек выручкой; ненацеленность на прибыль; при невозможности полного покрытия выручкой собственных издержек привлечение других источников финансирования деятельности (субсидии государства, поддержка фондов и т. д.).

Социальные кооперации представляют собой объединения граждан, нацеленные на достижения общественных выгод. В Российской Федерации к ним относятся производственные и потребительские кооперативы, которые могут в своей деятельности реализовывать социально-инновационные проекты.

Социальное партнёрство - система институтов и механизмов согласования интересов участников производственного процесса: работников и работодателей, основанная на равном сотрудничестве [10]. Развитие социального партнёрства в его различных формах - важная составная часть процесса усиления социальной направленности современной рыночной экономики, её социализации. В системе социального партнёрства интересы работников представлены, как правило, профсоюзами, интересы работодателей - союзами предпринимателей. В так называемом трипартистском её варианте третьим непосредственным участником процесса согласования интересов выступает государство, которое одновременно является и гарантом выполнения принятых соглашений. Согласование интересов достигается путём переговорного процесса, в ходе которого стороны договариваются об условиях труда и его оплате, о социальных гарантиях работникам и их роли в деятельности предприятия.

Развитие системы социального партнёрства создаёт возможность достижения относительного баланса интересов работников и работодателей на основе сотрудничества, компромисса, ведёт к социальному консенсусу. Оно служит действенным инструментом сочетания экономической эффективности и социальной справедливости.

\section{Заключение}

Проведенный анализ теоретических взглядов экономистов на сущность и содержание социальных инноваций позволил выявить, что их основными составляющими элементами являются новшество, необратимые изменения в сферах жизнедеятельности человека, решение общественных проблем, рост личного и общественного благосостояния. С учетом данных результатов теоретического анализа авторами были уточнены следующие позиции: новшество может определяться как с позиции предметного подхода (воплощаться в форме социальной услуги, продукта, проекта), так и носить процессный характер, принимая форму социально-инновационного процесса. В любом случае социальная инновация реализуется в сферах деятельности человека с целью улучшения качества его жизни, повышения благосостояния. На основе этих тезисов в авторской трактовке социальные инновации предстают как совокупность качественных изменений в сферах формирования, развития и реализации человеческого и социального капитала с целью повышения уровня личного и общественного благосостояния.

Кроме того, в процессе исследования было выявлено, что социальные инновации характеризуется такими признаками, как стратегическая направленность, инертность, синергизм, рискогенность.

Стратегическая направленность обусловлена проявлением социальных инноваций с позиции ключевого фактора трансформации социально-экономической системы в долгосрочной перспективе.

Под инертностью социальных инноваций подразумеваются любые действия ее субъектов, направленные на задержку или противодействие осуществлению социальных инноваций.

Внедрение социальных инноваций может сопровождаться возникновением эффекта синергии благодаря взаимодействию различных хозяйствующих субъектов между собой.

Социальные инновации характеризуются высокой степенью риска, так как их формирование, распространение и внедрение в практику зависят от качества социального капитала в социально-экономической системе.

Поскольку социальные инновации являются достаточно сложным социально-экономическим явлением, то в исследовании их субъектные формы были рассмотрены с позиций проектного и институционального подходов. Со- 
гласно проектному подходу участниками социальных инноваций являются заказчик, инвестор, производитель и потребитель. С позиции институционального подхода участниками социальных инноваций являются домохозяйства, фирмы и государство. Акцент в данном случае сделан на роли и функции домашних хозяйств, которые выступают как в качестве носителя человеческого капитала, так и непосредственного потребителя социальной инновации.

Необходимость в более детальном изучении содержательных и субъектных форм социальных инноваций обусловила потребность в разработке их классификации по следующим критериям: сферам общественной жизни, уровню и степени масштабности, институциональной форме выражения, субъектам взаимодействия.

В статье наибольшее внимание было уделено таким видам социальных инноваций, как социальное предпринимательство, социальное предприятие, социальные кооперации и социальное партнёрство.

При анализе данных видов социальных инноваций были сделаны следующие выводы:

- во-первых, социальное предпринимательство - это предпринимательская деятельность, нацеленная на смягчение или решение социальных проблем. Основная цель социальных предприятий - это решение социальных проблем инновационными методами, т. е. создание социального блага, посредством осуществления предпринимательской деятельности;

- во-вторых, социальное предприятие по сути и функциям идентично понятию «неком-

\section{Библиографический список}

1. Heiscala R. Social innovations: structural and power perspectives // Social Innovations, Institutional Change and Economic Performance. 2007. P. 52-79.

2. Khaustova Y., Breus S., Nevmerzhytska S., Tsalko T., Kharchenko T. Features of social entrepreneurship as a factor in the development of social innovation // Journal of Entrepreneurship Education. 2019. T. 22, no. 1.

3. Koroleva V. A. Socio-psychological features of the innovation process in the social sphere // Contemporary Problems of Social Work. 2017. T. 3, no. 2 (10). C. $146-152$. DOI: $10.17922 / 2412-5466-$ 2017-3-2-146-152

4. Phils J. Rediscovering Social Innovations. Stanford: Stanford Graduate School of Business, 2009. $122 \mathrm{p}$.

5. Pol E., Ville S. Social innovation: Buzz word or enduring term? // The Journal of Socio-Economics. 2009. No. 38. P. $878-885$. мерческая организация». Данная категория, кроме того, включает такие традиционные организации, как некоммерческие театры, госпитали, школы, производителей социальных услуг и т. д.;

- в-третьих, социальные кооперации представляют собой объединения граждан, нацеленные на достижения общественных выгод. В Российской Федерации к ним относятся производственные и потребительские кооперативы, которые могут в своей деятельности реализовывать социально-инновационные проекты;

- в-четвертых, социальное партнёрство - это система институтов и механизмов согласования интересов участников производственного процесса: работников, работодателей и профсоюзов, основанная на равном сотрудничестве.

В заключение сделан вывод о том, что типология социальных инноваций характеризуется большим разнообразием, многокритериальностью и значима как в теоретическом, так и в прикладном аспектах, поскольку выделение видов социальных инноваций позволяет сформировать целостное и завершенное представление об исследуемом объекте, а также выявлять приоритетные направления их развития с целью повышения личного и общественного благосостояния.

\section{Конфликт интересов}

Авторы декларируют отсутствие явных и потенциальных конфликтов интересов, связанных с публикацией настоящей статьи

6. Yun J. J., Zhao X., Park K. B., Im C. J., Shin C. H. Dynamics of social enterprises-shift from social innovation to open innovation // Science, Technology and Society. 2017. T. 22, no. 3. C. 425-439. DOI: 10.1177/ 0971721817723375

7. Башарина А. В. Социальные инновации в образовании: сущность и классификация // Известия Самарского научного центра Российской академии наук. 2009. Т. 11, № 4-5. С. 1101-1108.

8. Бухалова Н. А., Бухалов М. А. Инновационная инертность организации: причины и факторы развития антиинновационного поведения персонала // Вектор науки Тольяттинского государственного университета. Серия: Педагогика, психология. 2014. № 2 (17). С. 48-50.

9. Веретенникова А. Ю., Омонов Ж. К. Разработка и внедрение социальных инноваций в гражданском обществе // Журнал экономической теории. 2018. T. 15 , № 1. C. 86. DOI: $10.23683 / 2073-6606-$ 2018-16-3-35-59. 
10. Гаджиев Ю. А. Теоретические подходы к определению сущности инноваций // Sciences of Europe. 2016. № 6-1 (6). С. 25-29.

11. Гончаров Г. А. Взгляд на термин «социальные инновации» через призму концепции социального капитала // Вестник Воронежского государственного университета. Серия: Экономика и управление. 2014. № 2. С. 130-133.

12. Кисова A. E. Структура механизма формирования и реализации социальных инноваций // Экономика и предпринимательство. 2019. № 11 (112). С. 74-80.

13. Королева В. А. Исследование инноваций в социальной сфере в рамках психологических наук // Наука и инновации в XXI веке: актуальные вопросы, открытия и достижения : сб. статей VII Междунар. науч.-практ. конф., 2017. С. 234-237.

14. Курдюмов С. Синергетика - теория самоорганизации, идеи, методы, перспективы. М. : Знание, 1983. 64 с.

15. Негорожина А. В., Лазарева Н. В. Управление социальными инновациями // Гуманитарные основания социального прогресса: Россия и совре- менность : сб. статей Междунар. науч.-практ. конф. 2016. C. 291-295.

16. Омонов Ж. К., Веретенникова А. Ю. Институциональная сущность социальных инноваций // Журнал экономической теории. 2019. Т. 16, № 4. С. 862-868.

17. Пантелеева Т. С. Особенности инноваций в сфере социальной работы // Отечественный журнал социальной работы. 2003. № 2. С. 24-29.

18. Попов Е. В., Омонов Ж. К., Наумов И. В., Веретенникова А. Ю. Тенденции развития социальных инноваций // TERRA ECONOMICUS. 2018. T. 16, № 3. C. 35-59. DOI: 10.23683/2073-6606-2018-16-335-59

19. Ромащенко Т. Д., Кисова А. Е. Концептуальные основы социального предпринимательства // Экономика и предпринимательство. 2017. № 11 (88). С. 1140-1143.

20. Широкова Е. О. Формы реализации социально-инновационной деятельности // Наука и образование: сохраняя прошлое, создаем будущее : сб. статей XV Междунар. науч.-практ. конф. 2018. C. 221-223.
Ромащенко Татьяна Дмитриевна, доктор экономических наук, профессор кафедры экономики, маркетинга и коммерции, Воронежский государственный университет, Воронеж, Российская Федерация

E-mail: taroma-vrn@yandex.ru

ORCID ID: 0000-0003-1485-0244

Поступила в редакцию 03.08.2020

Подписана в печать 15.08.2020
Кисова Анна Евгеньевна, кандидат экономических наук, доцент кафедры экономики Липецкого государственного технического университета, Липецк, Российская Федерация

E-mail: zaumka84@mail.ru

ORCID ID: 0000-0001-7921-6303 


\title{
Social innovation: content, subject forms and classification
}

\author{
T. D. Romashchenko ${ }^{1}$, A. E. Kisova ${ }^{2} \bowtie$
}

${ }^{1}$ Voronezh State University, University pl., 1, 394018, Voronezh, Russian Federation

${ }^{2}$ Lipetsk State Technical University, Moskovskaya st., 30, 398055, Lipetsk, Russian Federation

Cite as: Romashchenko, T. D., Kisova, A. E. Social innovation: content, subject forms and classification // Proceedings of Voronezh State University. Series: Economics and Management. 2020. Vol. 3. Pp. 25-33. (In Russ., abstract in Eng.). DOI: 10.17308/econ.2020.3/3102

Importance. Social innovations have been the object of close attention of many domestic and foreign economists over the past twenty years. Their study is characterized by an interdisciplinary approach. Nevertheless, many important aspects of this phenomenon are insufficiently studied or are controversial. The latter include the essence of social innovations, their features and content characteristics, and subject forms. The above reasons lead to the need to classify social innovations according to a number of features that can be used to identify their categorical status, to identify distinctive features from such categories as innovations in the social sphere and innovations in the public sector.

Objectives. Author's study of the content of social innovation. Study of the subjective forms of social innovation from the standpoint of the project and institutional approach. Classification of social innovations according to criteria: according to the spheres of public life, according to the level and degree of scale, according to the institutional form of expression, according to the subjects of interaction.

Methods. In the process of achieving the set goals, a set of scientific approaches was used: historical-genetic, systemic, project-based, institutional, and structural. The work uses the techniques and methods of formal and dialectical logic (analysis and synthesis, comparisons, analogies, the unity of the historical and logical). The research is based on the study of current monographic and periodical economic literature.

Conclusions and Relevance. The conclusion is made about the understanding of social innovation as a set of qualitative changes in the areas of formation, development and implementation of human and social capital in order to increase the level of personal and social well-being. The specificity of social innovations is determined by their characteristics: strategic focus, inertia, synergy, riskiness. The participants in the social and innovative process are considered from the standpoint of the project and institutional approaches. Within the framework of the project approach, the main subjects are: customer, investor, manufacturer, consumer; within the institutional framework - households, firms, the state. The typology of social innovations is characterized by great diversity, multicriteria and is significant both in theoretical and applied aspects, since the identification of types of social innovations allows you to form a holistic and complete idea of the object under study, as well as to identify the priority directions of their development.

Key words: qualitative changes, types of social innovations, classification signs, social partnership, social entrepreneurship.

\section{Conflict of Interest}

The author declares the absence of obvious and potential conflicts of interest related to the publication of this article.

2. Khaustova, Y., Breus, S., Nevmerzhytska, S., Tsalko, T. \& Kharchenko, T. (2019) Features of social entrepreneurship as a factor in the development of social innovation. Journal of Entrepreneurship Education. 22 (1).

3. Koroleva, V. A. (2017) Socio-psychological features of the innovation process in the social sphere. Contemporary Problems of Social Work. 3 (2), 146-152. DOI: 10.17922/2412-5466-2017-3-2-146-152

\section{References}

1. Heiscala, R. (2007) Social innovations: structural and power perspectives. Social Innovations, Institutional Change and Economic Performance. 52-79.

4. Phils, J. (2009) Rediscovering Social Innovations. Stanford, Stanford Graduate School of Business.

5. Pol, E. \& Ville, S. (2009) Social innovation: Buzz word or enduring term? The Journal of Socio-Economics. 38, 878-885.

6. Yun, J. J., Zhao, X., Park, K. B., Im, C. J. \& Shin, C.H. (2017) Dynamics of social enterprises-shift from social innovation to open innovation. Science, Technology and Society. 22 (3), 425-439.DOI: 10.1177/0971721817723375. 
7. Basharina, A. V. (2009) [Social innovations in education: essence and classification]. Bulletin of the Samara Scientific Center of the Russian Academy of Sciences. 11 (4-5), 1101-1108. (In Russ.)

8. Bukhalova, N. A. \& Bukhalov, M. A. (2014) [Innovative inertia of the organization: reasons and factors of development of anti-innovative behavior of personnel]. Science Vector of Togliatti State University. Series: Pedagogy, Psychology. 2 (17), 48-50. (In Russ.)

9. Veretennikova, A. Y. \& Omonov, Zh. K. (2018) [Development and implementation of social innovations in civil society]. Journal of Economic Theory. 15, 86. (In Russ). DOI: 10.23683 / 2073-6606-2018-16-335-59.

10. Gadzhiev, Y.A. (2016) [Theoretical approaches to defining the essence of innovation]. Sciences of Europe, 6-1 (6), 25-29. (In Russ.)

11. Goncharov, G. A. (2014) [A look at the term "social innovation" through the prism of the concept of social capital]. Proceedings of Voronezh State University. Series: Economics and Management. 2, 130133. (In Russ.)

12. Kisova, A. E. (2019) [The structure of the mechanism for the formation and implementation of social innovations]. Economics and Entrepreneurship. 11 (112), 74-80. (In Russ.)

13. Koroleva, V.A. (2017) [Research of innovations in the social sphere in the framework of psychological sciences]. In [Science and innovation in the XXI century: topical issues, discoveries and achievements: a collection of articles of the VII International scientific and practical conference]. 234-237. (In Russ.)

14. Kurdyumov, S. (1983) [Synergetics - the theory of self-organization, ideas, methods, prospects]. Moscow, Knowledge. (In Russ.)

15. Negorozhina, A. V. \& Lazareva, N. V. (2016) [Management of social innovations]. In [Humanitarian foundations of social progress: Russia and the present: a collection of articles of the International Scientific and Practical Conference]. 291-295. (In Russ.)

16. Omonov, Zh. K. \& Veretennikova, A. Yu. (2019) [Institutional essence of social innovation]. Journal of economic theory. 4, 862-868. (In Russ.)

17. Panteleeva, T. S. (2003) [Features of innovations in the field of social work]. Domestic journal of social work. 2, 24-29. (In Russ.)

18. Popov, E. V., Omonov, Zh. K., Naumov, I. V, \& Veretennikova, A. Yu. (2018) [Trends in the development of social innovations]. Terra economicus. 16 (3), 35-59. (In Russ). DOI: 10.23683/2073-6606-2018-163-35-59.

19. Romashchenko, T. D. \& Kisova, A. E. (2017) [Conceptual Foundations of Social Entrepreneurship]. Economy and Entrepreneurship. 11 (88), 1140-1143. (In Russ.)

20. Shirokova, E. O. (2018) [Forms of implementation of social and innovative activity]. In [Science and education: preserving the past, creating the future: a collection of articles of the XV International scientific and practical conference]. 221-223. (In Russ.)
Tatyana D. Romaschenko, Dr. Sci. (Econ.), Prof., Department of Economics, Marketing and Commerce, Voronezh State University, Voronezh, Russian Federation

E-mail: taroma-vrn@yandex.ru

ORCID ID: 0000-0003-1485-0244
Anna E. Kisova, Assoc. Prof., Department of Economics, Lipetsk State Technical University, Lipetsk, Russian Federation

E-mail: zaumka84@mail.ru

ORCID ID: 0000-0001-7921-6303

Received 03.08.2020

Accepted 15.08.2020 